Article

\title{
Potential of Cell-Free Supernatant from Lactobacillus plantarum NIBR97, Including Novel Bacteriocins, as a Natural Alternative to Chemical Disinfectants
}

\author{
Sam Woong Kim ${ }^{1}{ }^{\oplus}$, Song I. Kang ${ }^{1}{ }^{\circledR}$, Da Hye Shin ${ }^{1}{ }^{\circledR}$, Se Yun $\mathrm{Oh}^{1}{ }^{1}$, Chae Won Lee ${ }^{2}$, \\ Yoonyong Yang ${ }^{2}$, Youn Kyoung Son ${ }^{2}$, Hee-Sun Yang ${ }^{2}$, Byoung-Hee Lee ${ }^{2}$, Hee-Jung An ${ }^{3}$, \\ In Sil Jeong ${ }^{4, *}$ and Woo Young Bang ${ }^{2, * \mathbb{D}}$ \\ 1 Gene Analysis Center, Gyeongnam National University of Science \& Technology, Jinju 52725, Korea; \\ swkim@gntech.ac.kr (S.W.K.); mole160104@naver.com (S.I.K.); nini1114@naver.com (D.H.S.); \\ ks-sy0809@naver.com (S.Y.O.) \\ 2 National Institute of Biological Resources (NIBR), Environmental Research Complex, Incheon 22689, Korea; \\ chaewon326@korea.kr (C.W.L.); tazemenia@korea.kr (Y.Y.); sophy004@korea.kr (Y.K.S.); \\ moeicy@korea.kr (H.-S.Y.); dpt510@korea.kr (B.-H.L.) \\ 3 Department of Pathology, CHA Bundang Medical Center, CHA University, Seongnam 13496, Korea; \\ hjahn@cha.ac.kr \\ 4 Center for Immune Cell Research, CHA Advanced Research Institute, Seongnam 13488, Korea \\ * Correspondence: insiljeong@gmail.com (I.S.J.); wybang@korea.kr (W.Y.B.); Tel.: +82-31-881-7374 (I.S.J.); \\ +82-32-590-7206 (W.Y.B.)
}

Received: 6 August 2020; Accepted: 21 September 2020; Published: 23 September 2020

\begin{abstract}
The recent pandemic of coronavirus disease 2019 (COVID-19) has increased demand for chemical disinfectants, which can be potentially hazardous to users. Here, we suggest that the cell-free supernatant from Lactobacillus plantarum NIBR97, including novel bacteriocins, has potential as a natural alternative to chemical disinfectants. It exhibits significant antibacterial activities against a broad range of pathogens, and was observed by scanning electron microscopy (SEM) to cause cellular lysis through pore formation in bacterial membranes, implying that its antibacterial activity may be mediated by peptides or proteins and supported by proteinase $\mathrm{K}$ treatment. It also showed significant antiviral activities against HIV-based lentivirus and influenza A/H3N2, causing lentiviral lysis through envelope collapse. Furthermore, whole-genome sequencing revealed that NIBR97 has diverse antimicrobial peptides, and among them are five novel bacteriocins, designated as plantaricin 1 to 5 . Plantaricin 3 and 5 in particular showed both antibacterial and antiviral activities. SEM revealed that plantaricin 3 causes direct damage to both bacterial membranes and viral envelopes, while plantaricin 5 damaged only bacterial membranes, implying different antiviral mechanisms. Our data suggest that the cell-free supernatant from L. plantarum NIBR97, including novel bacteriocins, is potentially useful as a natural alternative to chemical disinfectants.
\end{abstract}

Keywords: AMP; antimicrobial activity; antiviral activity; bacteriocin; COVID-19; disinfectant; Lactobacillus plantarum; plantaricin

\section{Introduction}

Severe acute respiratory syndrome coronavirus 2 (SARS-CoV-2), responsible for the global pandemic of coronavirus disease 2019 (COVID-19), is the foremost concern among recent global health issues [1]. For prevention of this infection, disinfectants have been widely used-mainly because SARS-CoV-2, like other coronaviruses and enveloped viruses, is surrounded by a fragile outer lipid envelope, which makes it more susceptible to disinfectants than non-enveloped viruses such as 
rotavirus, norovirus, and poliovirus [2]. Accordingly, the pandemic of COVID-19 has led to a large surge in demand for disinfectants, especially chemical disinfectants such as alcohol- or chlorine-based formulas for the disinfection of hands or environmental surfaces [3-5]. Although chemical disinfectants are considered very effective, they could be hazardous to users if they are not properly handled; for example, alcohol-based disinfectants are flammable and can be harmful to humans if they enter the body [3]. For this reason, there is increasing interest in disinfectants based on natural products.

Lactic acid bacteria, traditionally used in fermented foods, have been considered as interesting resources to contribute to developing a safe alternative to biocides, which are potentially hazardous to humans, because they produce diverse antimicrobial substances and are seldom hazardous to humans [6,7]; most are approved by the U.S. Food and Drug Administration as GRAS (Generally Recognized as Safe). As typical antimicrobial substances, they secrete lactic acid with bacteriocins and antimicrobial peptides (AMPs), which are produced by most microbes [6,7]. In particular, bacteriocins, such as nisin, sakacin, plantaricin, and leucocin from lactic acid bacteria have been reported to have antibacterial activity against foodborne bacteria, such as Escherichia coli, Salmonella enterica, and Listeria monocytogenes, and thus many studies have highlighted their application as natural alternatives to artificial preservatives and antibiotics [6,8-10]. In addition, several bacteriocins have shown antiviral activities against pathogenic viruses such as poliovirus, herpes simplex virus, and influenza viruses [10-12]. Accordingly, the cell-free supernatant, including the bacteriocins and lactic acid, has potential as a natural alternative to chemical disinfectants, although there have been no attempts to apply it as a disinfectant as of yet. To the best of our knowledge, this report is the first that addresses these issues.

In this study, we first suggest that the cell-free supernatant from Lactobacillus plantarum NIBR97, a lactic acid bacterium isolated from kimchi, a Korean fermented food, could potentially be useful for disinfection against both pathogenic bacteria and viruses, mediated by bacteriocins as well as lactic acid. Through the genomic analysis of the NIBR97 strain, we discovered novel bacteriocins functioning as antibacterial and antiviral peptides. Our study will provide important information that will guide new strategies to replace chemical disinfectants with natural substances.

\section{Results}

\subsection{Antibacterial Activity of Cell-Free Supernatant from L. plantarum NIBR97}

Lactobacillus plantarum NIBR97 were screened from kimchi as a strain with superior antibacterial activity, and its cell-free supernatant was further used for the examination of antibacterial activity, as shown in Figure 1. The minimum inhibitory concentrations (MIC50 and MIC90) were determined as 30.04 and $67.43 \mu \mathrm{g}$ total proteins/mL against Salmonella enterica Serovar Enteritidis (S. Enteritidis), respectively, which indicates significantly higher antibacterial activity than the three Lactobacillus plantarum strains, KCTC33131, KCTC21004, and KCTC13093, with higher MIC50 and MIC90 values than NIBR97 (Figures 1A and S1A). The cell-free supernatant also showed MIC50s and MIC90s against Salmonella Gallinarum, Edwardsiella tarda, Pasteurella multocida, and Streptococcus iniae (Figures 1B and S1B), implying antibacterial activity against broad pathogenic bacteria. In addition, when Escherichia coli and Staphylococcus aureus were treated with the cell-free supernatant for $5 \mathrm{~min}$, they showed a reduction of at least $99.9 \%\left(\geq 3 \log _{10}\right)$ of the total count in the original inoculum (Figure 1C), indicating bactericidal activity and potential as a disinfectant. 


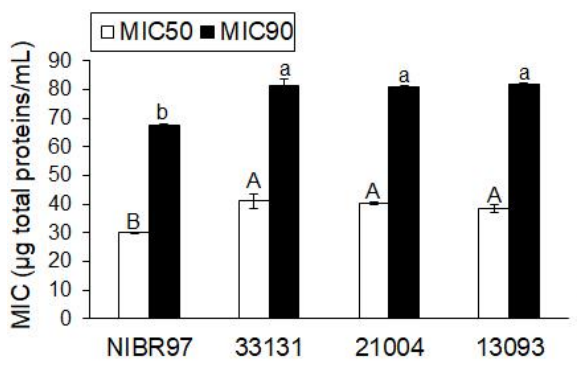

(A)

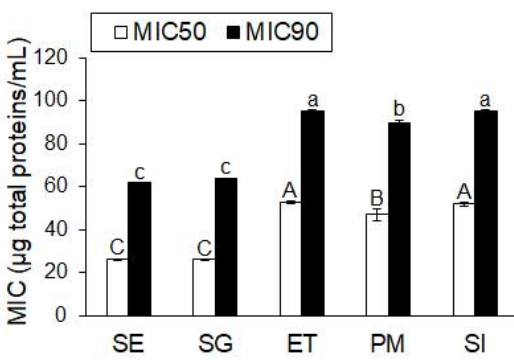

(B)

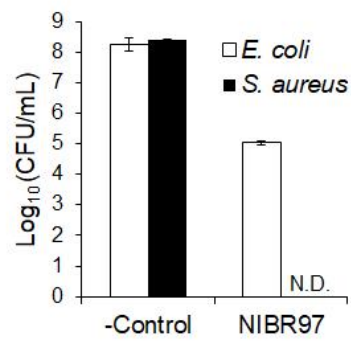

(C)

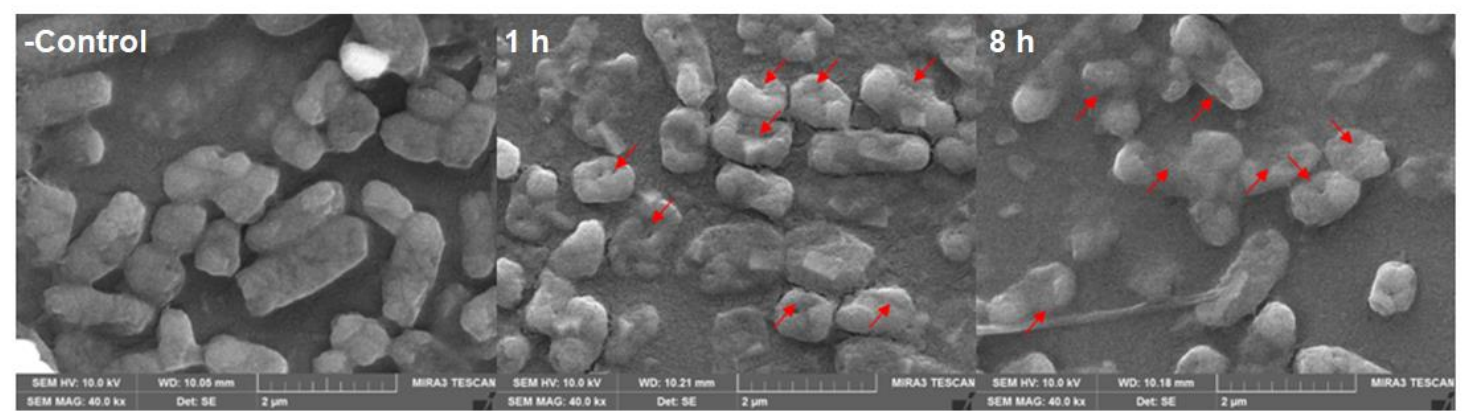

(D)

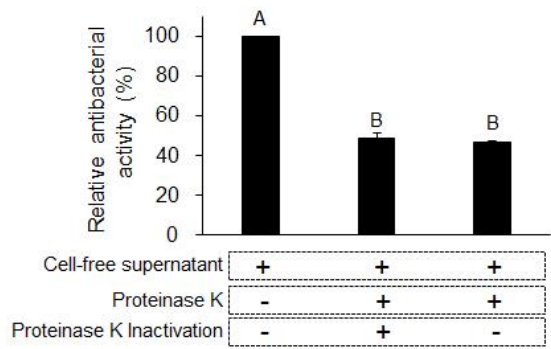

(E)

Figure 1. Antibacterial activity of cell-free supernatant from Lactobacillus plantarum NIBR97. Antibacterial activities of the cell-free supernatant from the L. plantarum strains NIBR97, KCTC33131, KCTC21004, and KCTC13093 were examined against Salmonella Enteritidis, whose MIC50s and MIC90s were determined (A). The MIC50s and MIC90s of the cell-free supernatant were determined against Salmonella Gallinarum (SG), Edwardsiella tarda (ET), Pasteurella multocida (PM), and Streptococcus iniae (SI), as well as S. Enteritidis (SE) (B). For bactericidal activity, Escherichia coli and Staphylococcus aureus were treated with the cell-free supernatant $(126.6 \mu \mathrm{g}$ total proteins $/ \mathrm{mL})$ for $5 \mathrm{~min}$, and then were counted to determine the titer $\left(\log _{10}\right.$ (colony-forming unit $\left.(\mathrm{CFU}) / \mathrm{mL}\right)$ and reduction rate $(\%)(\mathrm{C})$. For scanning electron microscopy, $S$. Enteritidis was treated without (control) or with the cell-free supernatant (70.8 $\mu \mathrm{g}$ total proteins $/ \mathrm{mL}$, MIC against $S$. Enteritidis) for $1 \mathrm{~h}$ and $8 \mathrm{~h}(\mathrm{D})$. The red arrows indicate the pores forming in the Salmonella membrane. (E) To investigate the effect of protease on the antibacterial activity of the cell-free supernatant, we added the proteinase $\mathrm{K}(100 \mu \mathrm{g} / \mathrm{mL})$ to the cell-free supernatant at $70.8 \mu \mathrm{g}$ total proteins $/ \mathrm{mL}$ and the treated sample was used to examine its antibacterial activity against S. Enteritidis. In (E), the plus (+) mark indicates the treatment of cell-free supernatant or proteinase K, whereas the minus (-) mark does no treatment, and the proteinase $\mathrm{K}$ was inactivated at $80^{\circ} \mathrm{C}$ for $10 \mathrm{~min}$ $(+)$ or not (-). The different letters (A, B, C, a, b and c) in the graphs ((A), (B), (C) and (E)) represent significant differences $(p<0.05)$ and in $(\mathbf{A})$ and $(\mathbf{B})$, the capital $(\mathrm{A}, \mathrm{B}$ and $\mathrm{C})$ and small letters $(\mathrm{a}, \mathrm{b} \mathrm{c})$ indicate the significant differences in MIC50 and MIC90 data, respectively.

In order to prove the antibacterial activity against pathogenic bacteria with the cell-free supernatant from L. plantarum NIBR97, we observed the $S$. Enteritidis treated with the cell-free supernatant using scanning electron microscopy (SEM). As shown in Figure 1D, the SEM images revealed that the cell-free supernatant effectively caused the Salmonella death via pore formation by cellular penetrating peptides, 
as is the case for typical AMPs [13]. Furthermore, when the cell-free supernatant was treated with proteinase $\mathrm{K}$, its antibacterial activity against $S$. Enteritidis decreased by about $50 \%$ compared with the control without the proteinase K treatment (Figure 1E). Therefore, we suggest that proteins or peptides play major roles for the antibacterial activities of cell-free supernatant from L. plantarum NIBR97.

\subsection{Antiviral Activity of Cell-Free Supernatant from L. plantarum NIBR97}

To assess its antiviral activity, the cell-free supernatant from L. plantarum NIBR97 was exposed to green fluorescent protein (GFP)-labeled lentiviruses, based on human immunodeficiency virus (HIV), which causes acquired immunodeficiency syndrome (AIDS), for 5 min and 24 h, as shown in Figure 2. When the GFP-labeled lentiviruses, treated with the cell-free supernatant, infected the HEK-293T cells (human host cells), they were observed by fluorescence microscopy to decrease dose- and time-dependently within the host cells (Figure 2A, the GFP images) without any cytotoxic effect on the human host cells (Figure 2A, the Bright images). SEM also confirmed its antiviral activity by showing that the cell-free supernatant effectively causes lentiviral lysis through the collapse of envelopes after 5 min (Figure 2B). In addition, when the human influenza A virus subtype H3N2 (A/H3N2) was treated with the cell-free supernatant, it showed a reduction of at least $99.5 \%$ of the total count of its original inoculums, which increased until 99.999\% with treatment time (Table 1). These results indicate that the cell-free supernatant from L. plantarum NIBR97 has superior antiviral activity, as well as potential as a disinfectant.

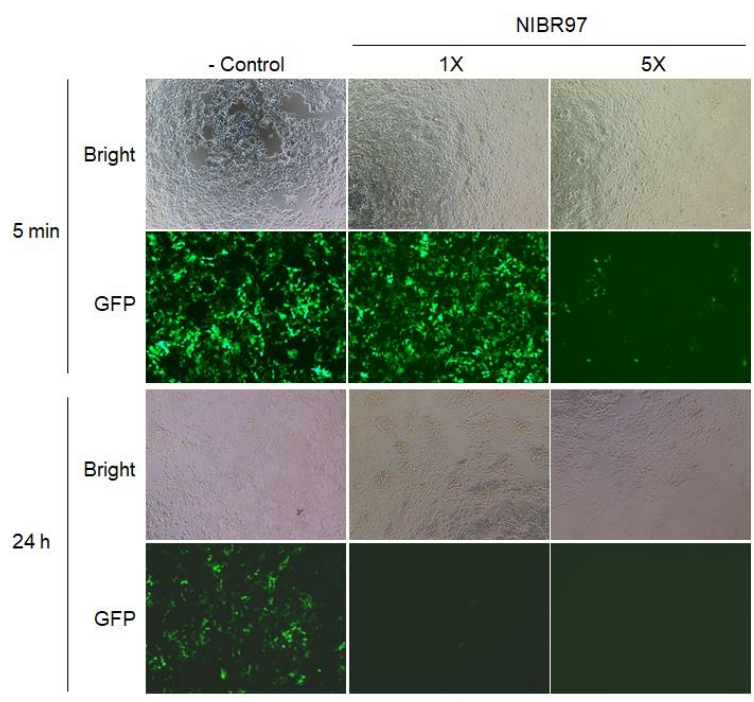

(A)

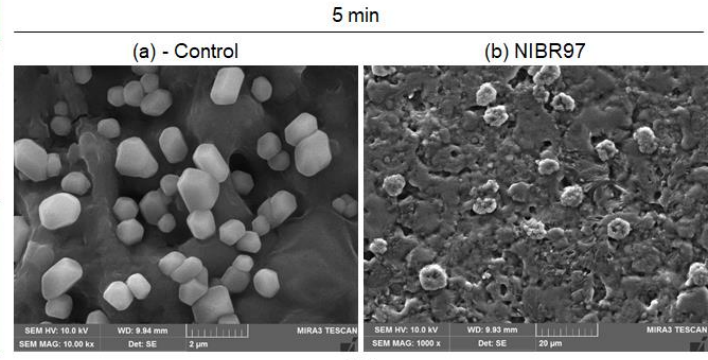

(B)

Figure 2. Antiviral activity of cell-free supernatant from L. plantarum NIBR97. (A) For fluorescence microscopy, we treated GFP-labeled lentiviruses with the cell-free supernatant for $5 \mathrm{~min}$ and $24 \mathrm{~h}$, and then were infected in HEK-293T human host cells. The $1 \times$ and $5 \times$ correspond to the concentrations treated to the lentiviruses, 79.15 and $395.75 \mu \mathrm{g}$ total proteins $/ \mathrm{mL}$, respectively. The bright-field images (Bright) indicate the HEK-293T cells, and the green signals in the fluorescent images (GFP) represent the GFP-labeled lentiviruses. (B) For scanning electron microscopy, the GFP-labeled lentiviruses were treated without (a) or with the cell-free supernatant $(395.75 \mu \mathrm{g}$ total proteins $/ \mathrm{mL})(\mathbf{b})$ for $5 \mathrm{~min}$. 
Table 1. Disinfection activity of the cell-free supernatant from L. plantarum NIBR97 against A/H3N2.

\begin{tabular}{|c|c|c|c|c|c|c|}
\hline \multirow{2}{*}{ Treatments ${ }^{1}$} & \multicolumn{2}{|c|}{$10 \min ^{1}$} & \multicolumn{2}{|c|}{$30 \min ^{1}$} & \multicolumn{2}{|c|}{$18 \mathrm{~h}^{1}$} \\
\hline & Titer $^{2}$ & Reduction $^{3}$ & Titer $^{2}$ & Reduction $^{3}$ & Titer $^{2}$ & Reduction $^{3}$ \\
\hline Water & 5.66 & 0 & 5.45 & 0 & 5.34 & 0.21 \\
\hline NIBR97 & 3.27 & 99.594 & $<0.51$ & $>99.999$ & $<0.51$ & $>99.999$ \\
\hline
\end{tabular}

${ }^{1} \mathrm{The} \mathrm{A} / \mathrm{H} 3 \mathrm{~N} 2$ viruses were treated with water, a negative control, or the cell-free supernatant (NIBR97) for $10 \mathrm{~min}$, $30 \mathrm{~min}$, and $18 \mathrm{~h} ;{ }^{2}$ and ${ }^{3}$ indicate the viral titer ( $\left.\log _{10} \mathrm{CCID} 50\right)$ and reduction (\%), respectively.

\subsection{Discovery of Novel Bacteriocins by the Genomic Analysis of L. plantarum NIBR97}

Analysis of the whole-genome sequence for the L. plantarum NIBR97 was carried out by the PacBio RS II (Pacific Biosciences, Menlo Park, CA, USA) sequencing platform to identify the AMPs from the NIBR97. The NIBR97 genome identified from de novo assembly was composed of a single circular bacterial chromosome and four plasmids, containing 2927 predicted open reading frames (ORFs), 68 tRNAs, and 16 rRNAs (Table 2 and Figure S2). Among the ORFs, 10 were identified to encode homologous proteins with known AMPs via an NCBI (National Center for Biotechnology Information) homology BLAST (Basic Local Alignment Search Tool) (Table S1). Furthermore, their expression in L. plantarum NIBR97 was confirmed by the transcriptomic data (Table S2). In detail, the five ORFs—orf02155, orf02163, orf02164, orf02421, and orf00645-were found to have $100 \%$ identities with plantaricin N, F, and E, as well as bacteriophage holing and lysozyme, known previously as AMPs from the Lactobacillus genus (Table S1). Five ORFs—orf00467, orf01336, orf01363, orf01599, and orf01790 — which were previously uncharacterized until now, were discovered in this study to consist of amino acid sequences with high positives $(>60 \%)$ with AMPs undiscovered in L. plantarum strains: grammistin Pp3, indolicidin, bactofencin A, hymenochirin-5B, and latarcin-2a, (Table S1). Thus, we herein designated the AMPs as novel bacteriocins called plantaricin (Pln) 1, 2, 3, 4, and 5 (Table S1). Interestingly, their structural models revealed that the three plantaricins-Pln 1, 4 and 5-form helix structures, and the two plantaricins-Pln 2 and 3-form random coil structures (Figure 3), similar to typical AMPs [14,15], implying that they may have antibacterial activities.

\subsection{Antibacterial and Antiviral Activities of Plantaricins from L. plantarum NIBR97}

To confirm whether the five Plns function as AMPs, we assessed their synthetic peptides for antibacterial activity against Salmonella Typhimurium (Figure S3). Among them, Pln 5 exhibited the highest antimicrobial activity, showing the lowest MIC50 compared with others, whereas Pln 4 showed the lowest antimicrobial activity (Figure S3). In addition, the Pln 3 and 5 were identified to inhibit the growth of Salmonella Enteritidis (Figure 4A) and were observed by SEM to effectively cause cellular lysis by damaging the membrane of $S$. Enteritidis via pore formation (Figure 4B), as did the cell-free supernatant from L. plantarum NIBR97 (Figure 1D).

Table 2. Summary of the de novo genome assembly of L. plantarum NIBR97.

\begin{tabular}{|c|c|c|c|c|c|}
\hline Items & Contig 1 & Contig 2 & Contig 3 & Contig 4 & Contig 5 \\
\hline Form & A circular chromosome & A circular plasmid & A circular plasmid & A linear plasmid & A linear plasmid \\
\hline Length ${ }^{1}$ & $3,022,780$ & 61,378 & 32,520 & 7394 & 6876 \\
\hline $\mathrm{GC}^{2}$ & 44.74 & 39.22 & 39.59 & 34.33 & 35.67 \\
\hline $\mathrm{ORF}^{3}$ & 2816 & 60 & 32 & 10 & 9 \\
\hline rRNA $^{4}$ & 16 & 0 & 0 & 0 & 0 \\
\hline tRNA $^{5}$ & 68 & 0 & 0 & 0 & 0 \\
\hline
\end{tabular}

${ }^{1}$ and ${ }^{2}$ indicate the length (bp, base pair) and GC (guanine-cytosine) contents ( $\%$ ) of contig in the form, respectively;

3,4 , and ${ }^{5}$ represent the number of predicted open reading frames (ORFs), rRNA, and tRNA, respectively. 

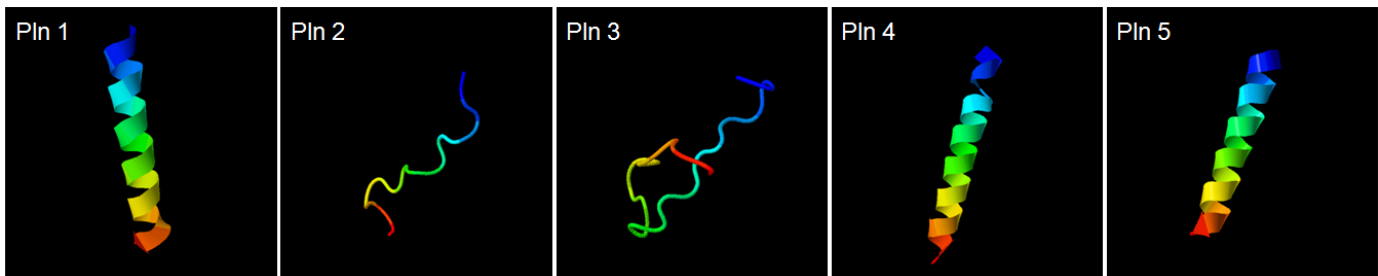

Figure 3. Structural models of plantaricins. Pln 1, 2, 3, 4, and 5 comprise the amino acid sequences VLGSLIGSVGIGVLSSLAARYK, IYPEKQPEEPVRR, KKSRRCQVYNNGMPTGMYTSC, PIVREPFKAMAVGIILAVMSGLLVT, and KAKKRFLRNRLSQQARKARTK, respectively. Pln 1, 4, and 5 form helix structures, and Pln 2 and 3 form random coil structures. The structures of $P \ln 1,2,3,4$, and 5 were predicted by the automated I-TASSER server (https://zhanglab.ccmb.med.umich.edu/I-TASSER/).

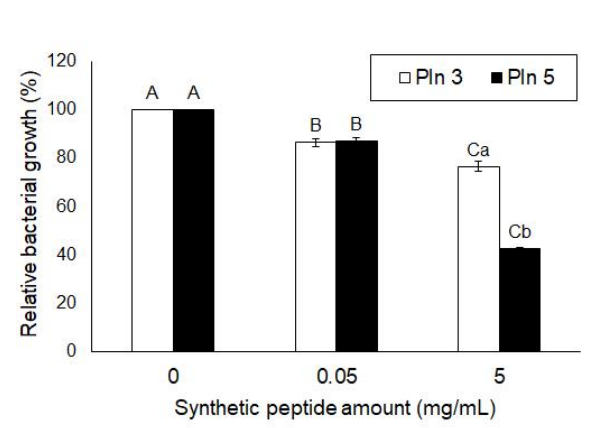

(A)

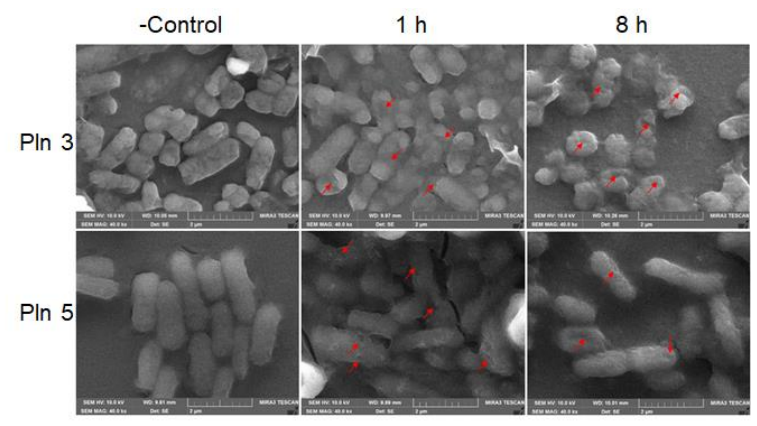

(B)

Figure 4. Antibacterial activity of plantaricin 3 and 5 against $S$. Enteritidis. $P \ln 3$ and 5 were synthesized according to the amino acid sequences in Figure 3, and further examined for their antibacterial activity against $S$. Enteritidis (A). The $y$-axis and different letters (A, B, C, a and b) in the graphs represent the relative bacterial growth $(\%)$ and significant differences $(p<0.05)$, respectively. In $(\mathrm{A})$, the capital $(\mathrm{A}, \mathrm{B}$ and $\mathrm{C})$ and small letters $(a$ and $b)$ indicate the significant differences between different concentrations $(0-5 \mathrm{mg} / \mathrm{mL})$ and the ones between Pln 3 and 5, respectively. (B) For scanning electron microscopy, $S$. Enteritidis was treated without or with synthetic Pln 3 or $5(5 \mathrm{mg} / \mathrm{mL})$ for $1 \mathrm{~h}$ and $8 \mathrm{~h}$. The red arrows indicate the pores forming in the Salmonella membrane.

The synthetic Pln 3 and 5 were further examined for antiviral activity against GFP-labeled lentiviruses. The synthetic peptides exhibited a cytotoxicity on the human host cells when the lentiviruses were treated with $5 \mu \mathrm{g} / \mu \mathrm{L}$ of synthetic peptides, but not with $\approx 2.5 \mu \mathrm{g} / \mu \mathrm{L}$ of synthetic peptides (Figure 5 , the Bright images). The fluorescence microscopy revealed that the lentiviruses decreased considerably within the host cells when they were treated with the Pln 3 or 5 for 24 h, but not for 5 min (Figure 5, the GFP images). This suggests that Pln 3 and 5 can considerably suppress viral infection in host cells. Interestingly, SEM revealed that Pln 3 effectively caused lentiviral lysis through the collapse of the envelopes (Figure 6), as the cell-free supernatant did (Figure 2B), whereas Pln 5 did not (Figure 6). This implies that $\mathrm{Pln} 3$ and 5 may exert their antiviral role through different mechanisms. 


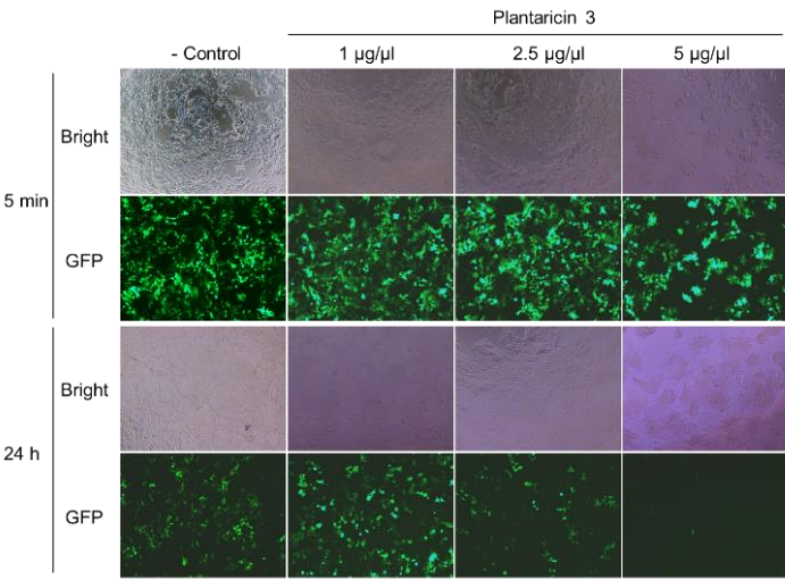

(A)

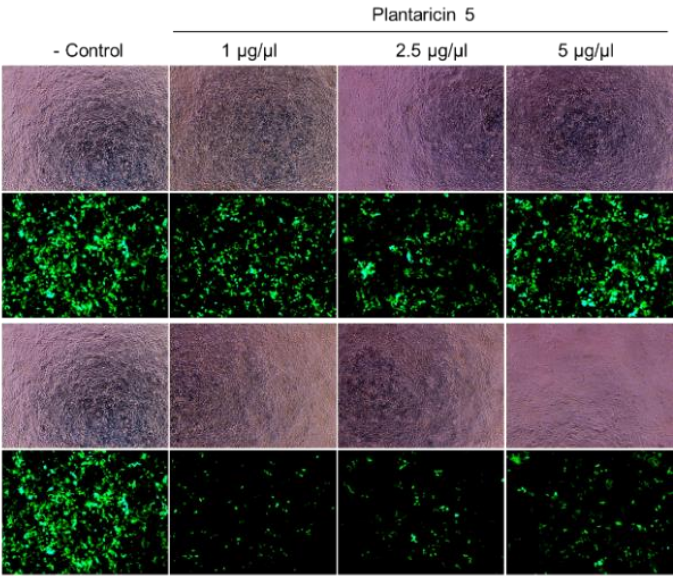

(B)

Figure 5. Fluorescence micrographs of HEK-293T cells infected with GFP-labeled lentiviruses treated with synthetic Pln 3 and 5 . The lentiviruses were treated without (control) or with the synthetic peptides (1 to $5 \mu \mathrm{g} / \mu \mathrm{L}$ ) Pln 3 (A) and 5 (B) for $5 \mathrm{~min}$ or $24 \mathrm{~h}$, and then the HEK-293T human host cells were infected. The bright-field images (Bright) indicate the HEK-293T cells, and the green signals in the fluorescent images (GFP) represent the GFP-labeled lentiviruses.
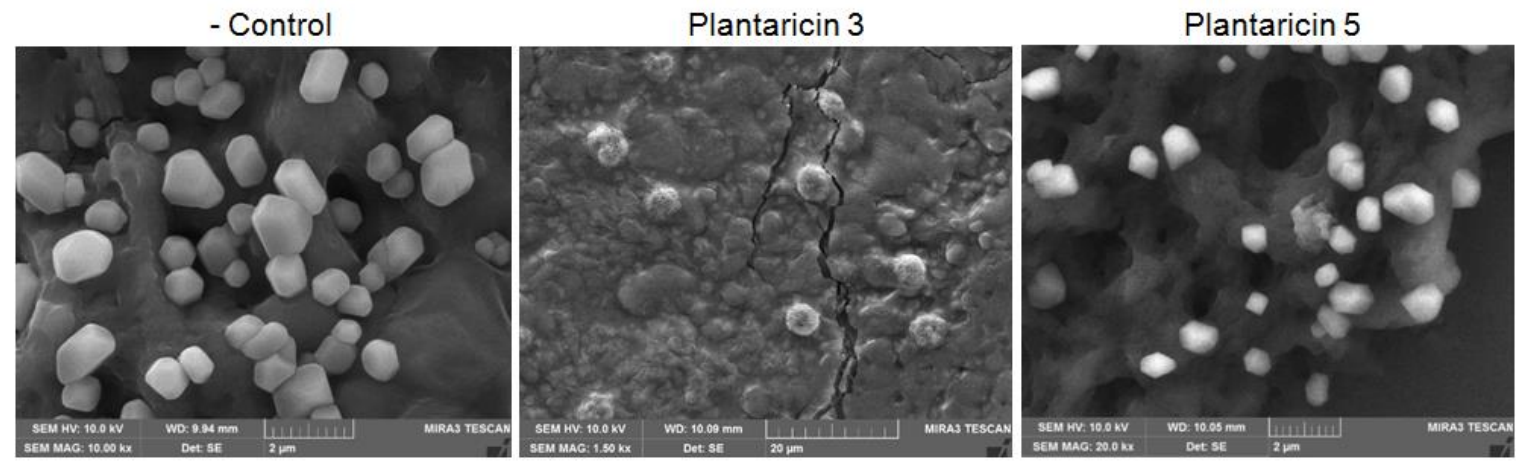

Figure 6. Scanning electron micrographs of the GFP-labeled lentiviruses treated with synthetic Pln 3 and 5 . The lentiviruses were treated without or with the synthetic peptides at $5 \mu \mathrm{g} / \mu \mathrm{L}$ for $24 \mathrm{~h}$.

\section{Discussion}

Lactobacillus plantarum is one of the most widespread lactic acid bacteria species and is largely used for the production of fermented products of animal and plant origin [16]. Moreover, some strains are known to produce several natural antibacterial substances, such as bacteriocins, organic acids (mainly lactic and acetic acid), and hydrogen peroxide [17,18], and thus many studies have highlighted their application as preservatives and antibiotics $[6,8-10]$. Here, we investigated their potential as a natural alternative to chemical disinfectants.

In this study, the NIBR97 strain was screened from kimchi, a Korean fermented food, and its cell-free supernatant was identified to have higher antibacterial activity against Salmonella bacteria than other L. plantarum strains (Figure 1A), as well as possessing antibacterial activities against a broad range of pathogenic bacteria (Figure 1B). It exhibited significant disinfection activities against the human pathogens influenza A virus H3N2, Escherichia coli, and Staphylococcus aureus, reducing them by at least $99.9 \%$ of the total count of their original inoculums within $30 \mathrm{~min}$ (Figure $1 \mathrm{C}$ and Table 1 ). These results indicate that the cell-free supernatant from L. plantarum NIBR97 has potential as a natural disinfectant, and thus further investigations were performed to identify the antimicrobial substances, such as AMPs, in the NIBR97 strain.

AMPs are small peptides composed of 10 to 40 amino acids, which cause microbial membrane modification via either pore formation by cell-penetrating property through a barrel stave or a 
toroidal pore mechanism, or through a non-pore carpet-like mechanism [13,19]. Our scanning electron micrographs of $S$. Enteritidis showed clearly that the cell-free supernatant from the NIBR97 formed a pore on the Salmonella surface (Figure 1D), as do typical AMPs [13]. Proteinase K treatment of the cell-free supernatant led to a considerable decrease in its antibacterial activity against both $S$. Enteritidis and S. Gallinarum (Figure 1E). Thus, these results confirm that the antibacterial activities of the cell-free supernatant from the NIBR97 are mediated mainly by its proteins or peptides, functioning as AMPs. The scanning electron micrographs of GFP-labeled lentivirus showed that the cell-free supernatant causes lentiviral lysis through envelope collapse (Figure 2A), but it was unclear whether the AMPs were involved in the envelope collapse of the virus.

Finally, to identify AMPs from the NIBR97 strains, we performed whole-genome sequencing, which revealed that the 10 ORFs encoded AMPs, including known forms (plantaricin E, F, N; bacteriophage holin; lysozyme) and novel forms (Pln 1 to 5 (Table S1)). In the case of the known AMPs, plantaricin E, F, and N are bacteriocins produced in Lactobacillus plantarum C11 [20]; holin, produced by bacteriophages, triggers and controls the degradation of the cell wall of the host bacteria [21]; and lysozyme functions as 1,4-beta-N-acetylmuramidase, an antimicrobial enzyme, and has been found mainly in Lactobacillus rhamnosus strains [22]. Interestingly, five ORFs were discovered as novel bacteriocins in this study (Figure 3) and were designated as Pln 1, 2, 3, 4, and 5. They were further confirmed as being expressed in the NIBR97 strain through transcriptomic sequencing (Table S2), and even their synthetic peptides exhibited antibacterial activity against Salmonella Typhimurium (Figure S3). The synthetic Pln 3 and 5 also inhibited the growth of $S$. Enteritidis and effectively caused cellular lysis through damage to the Salmonella membrane via pore formation (Figure 4), suggesting that they function as AMPs. However, the synthetic Plns showed overall lower antibacterial activities than antibiotics such as octenidine when their MICs were compared with each other (Figure S3) [23]. This is presumably because the Plns were not synthesized on the basis of complete amino acid sequences for the optimal antibacterial activity but were done on the basis of minimal sequences for the activity; thus, it is further necessary to identify the mature peptide sequence responsible for the optimal antibacterial activity, following the signal peptide cleavage. Moreover, Pln 3 and 5 were identified to suppress lentiviral infection in human host cells (Figure 5). Collectively, these results suggest that the cell-free supernatant from L. plantarum NIBR97 may include AMPs, such as $P \ln 3$ and 5, exhibiting antibacterial and antiviral activities. However, Pln 3 and 5 were observed by SEM to act differentially in the suppression of viral infection; Pln 3 had a significant effect on the viral shape through the collapse of the viral envelope, which suggests that it may cause direct damage to the envelope. In contrast, Pln 5 had little effect on it (Figure 6), which implies that it may interfere with the interaction between viruses and host cells [24,25].

Noticeably, Pln 3 and 5 suppressed viral infection when used against lentivirus for $24 \mathrm{~h}$, but not for $5 \mathrm{~min}$ (Figure 5), which indicates that long exposure is required for their antiviral role. Although the Plns exhibited low antibacterial activities as mentioned above, during long expose (i.e., $24 \mathrm{~h}$ ), they may also contribute significantly to the antibacterial activities of cell-free supernatant, together with other AMPs discovered by genomic analysis of NIBR97, which is strongly supported by the proteinase K treatment leading to a considerable decrease $(>50 \%)$ in antibacterial activity of the cell-free supernatant (Figure 1E). Furthermore, this is confirmed by Figure S4-the cell-free supernatant from the E. coli Top10 strain (Invitrogen, Carlsbad, CA, USA), harboring each Pln gene cloned, showed significant antibacterial activities against both Gram-negative and Gram-positive bacteria, whereas very little antibacterial activity was detected in the negative control, that is, treatment with the cell-free supernatant from the strain without the Pln genes (Figure S4). Meanwhile, the disinfection activity of the cell-free supernatant during short exposures (i.e., within $30 \mathrm{~min}$ ), as shown in Figure $1 \mathrm{C}$ and Table 1, was presumably because the lactic acid may have functioned as a disinfectant during the short exposure. This is supported by the data, showing that the cell-free supernatant contained considerable lactic acids $(\approx 2 \%)$ when the NIBR97 strain was cultured in the de Man, Rogosa and Sharpe (MRS) medium, consisting of $5 \%$ solutes and $95 \%$ water, for $24 \mathrm{~h}$ (Figure S5), and by a previous report stating that they induce sudden severe acid stress, leading to a shock of oxidative stress and resulting in the destabilization of 
the bacterial membrane [26]. Therefore, the cell-free supernatant may exert its role as a disinfectant, mainly through lactic acid during short exposure (i.e., within $30 \mathrm{~min}$ ), while it does so through an integrated effect between the lactic acid and the various AMPs during long exposure (i.e., 24 h).

\section{Materials and Methods}

\subsection{Materials}

As susceptible bacteria to AMPs, S. Enteritidis, S. Gallinarum, Edwardsiella tarda, Pasteurella multocida, and Streptococcus iniae were obtained from Dr. Jin Hur (Chonbuk National University, Iksan, Korea) and Dr. Tae Sung Jung (Gyeongsang National University, Jinju, Korea). The Lactobacillus plantarum strains KCTC33131, KCTC21004, and KCTC13093, as well as the susceptible bacteria Escherichia coli ATCC 10536 and Staphylococcus aureus ATCC 6538, were purchased from KCTC (Korean Collection for Type of Cultures, Daejeon, Korea). The human influenza A/H3N2 was provided by the Korea Centers for Disease Control and Prevention (KCDC, Chungcheongbuk-do, Korea). The plasmids for lentiviral packaging (two packaging vectors, $\mathrm{pRSV}-\mathrm{Rev}$ and $\mathrm{pCgpV}$, and an envelope vector, $\mathrm{pCMV-VSV-G}$ ) and for a positive control of transduction (pSIH1-H1-siLUC-copGFP) were purchased from Cellbiolab (San Diego, CA, USA) and System Biosciences (Palo Alto, CA, USA), respectively. The five synthetic peptides-plantaricin 1 to 5-were purchased from Cosmogenetech Inc. (Seoul, Korea).

\subsection{Analysis of the Minimal Inhibitory Concentration (MIC50 and MIC90)}

L. plantarum NIBR97 was incubated at $37^{\circ} \mathrm{C}$ for $24 \mathrm{~h}$ in an MRS liquid medium (10 g/L peptone, $8 \mathrm{~g} / \mathrm{L}$ meat extract, $4 \mathrm{~g} / \mathrm{L}$ yeast extract, $20 \mathrm{~g} / \mathrm{L} \mathrm{d}(+)$-glucose, $2 \mathrm{~g} / \mathrm{L}$ dipotassium hydrogen phosphate, $5 \mathrm{~g} / \mathrm{L}$ sodium acetate trihydrate, $2 \mathrm{~g} / \mathrm{L}$ triammonium citrate, $0.2 \mathrm{~g} / \mathrm{L}$ magnesium sulfate heptahydrate, and $0.05 \mathrm{~g} / \mathrm{L}$ manganous sulfate tetrahydrate). The cultural broth was centrifuged for $20 \mathrm{~min}$ at $2000 \times g$, and the centrifugal supernatant was collected and then sterilized by a $0.22 \mu \mathrm{m}$ filtration. The sterilized fluid was either applied directly for the examination of antimicrobial activity or fractionated and stored at $-80^{\circ} \mathrm{C}$ until use. The assessment of antimicrobial activity on a microtiter plate was performed by some modification of the dilution assay of Wiegand et al. [27]. The MIC50 and MIC90 were expressed as total proteins equivalent $(\mu \mathrm{g})$ per volume $(\mathrm{mL})$ of the sample, and the effect of proteinase $\mathrm{K}$ treatment was examined by a previously described procedure [28].

\subsection{Measurement of Bactericidal Activity}

The susceptible bacterial strains Escherichia coli ATCC 10536 and Staphylococcus aureus ATCC 6538 were adjusted into 1.5 to $5.0 \times 10^{8} \mathrm{CFU} / \mathrm{mL}$ after pre-culture, and $10 \%$ sucrose was used as an interfering agent, $0.25 \mathrm{M} \mathrm{KH}_{2} \mathrm{PO}_{4}$ ( $\mathrm{pH} 7.2$ ) was used as a neutralizing agent, and $20 \mathrm{mg} / \mathrm{mL}$ proteinase $\mathrm{K}$ was used to degrade the AMPs. For the bactericidal activity assay, we mixed $100 \mu \mathrm{L}$ of prepared susceptible bacterial solution, $100 \mu \mathrm{L} \mathrm{10 \%} \mathrm{sucrose,} \mathrm{and} 800 \mu \mathrm{L}$ cell-free supernatant $(126.6 \mu \mathrm{g}$ total proteins/mL) from L. plantarum NIBR97 and reacted the mixture at $20{ }^{\circ} \mathrm{C}$ for $5 \mathrm{~min}$. An aliquot $(100 \mu \mathrm{L})$ of the reaction solution was mixed with $800 \mu \mathrm{L} 0.25 \mathrm{M} \mathrm{KH}_{2} \mathrm{PO}_{4}(\mathrm{pH} 7.2), 5 \mu \mathrm{L}$ proteinase $\mathrm{K}$, and $100 \mu \mathrm{L}$ distilled water, and then reacted at $20^{\circ} \mathrm{C}$ for $5 \mathrm{~min}$. The surviving cells were counted by serial dilution of the treated solution and incubation on an Luria-Bertani (LB) plate.

\subsection{Scanning Electron Microscopy (SEM)}

The $S$. Enteritidis was treated with the cell-free supernatant $(70.8 \mu \mathrm{g}$ total proteins/mL, MIC against $S$. Enteritidis) from L. plantarum culture or the synthetic peptides, Pln $3(1 \mu \mathrm{g} / \mu \mathrm{L})$ or Pln 5 $(1 \mu \mathrm{g} / \mu \mathrm{L})$, for 0,1 , and $8 \mathrm{~h}$, and the lentivirus was assessed with the cell-free supernatant $(15.8 \mu \mathrm{g}$ total proteins/mL) for $5 \mathrm{~min}$ and with the synthetic peptides Pln $3(5 \mu \mathrm{g} / \mu \mathrm{L})$ or Pln $5(5 \mu \mathrm{g} / \mu \mathrm{L})$ for $24 \mathrm{~h}$. The treated bacteria and viruses were observed by a scanning electron microscope according to previously described procedures [28]. 


\subsection{Antiviral Analysis Against Influenza A/H3N2}

For the antiviral test, we co-incubated $0.1 \mathrm{~mL}$ of the A/H3N2 soup $\left(2-4 \times 10^{5}\right.$ viruses $\left./ \mu \mathrm{L}\right)$ with $0.9 \mathrm{~mL}$ of the cell-free supernatant $(142.5 \mu \mathrm{g}$ total proteins $/ \mathrm{mL})$ for $10 \mathrm{~min}, 30 \mathrm{~min}$, and $18 \mathrm{~h}$ at $25^{\circ} \mathrm{C}$. After the co-incubation, the cell-free supernatant-A/H3N2 mixture was 10-fold serially diluted to infect Madin-Darby canine kidney (MDCK) cells $\left(3 \times 10^{4}\right.$ cells per well) and, thereafter, the cell culture infectious dose (CCID50) and the viral reduction were determined by cytopathic effect (CPE) and plaque assays, as previously described [29].

\subsection{Antiviral Analysis Against GFP-Labeled Lentivirus}

For the production of GFP-labeled lentivirus, we transfected $5 \mu \mathrm{g}$ of pRSV-Rev, $5 \mu \mathrm{g}$ of pCMV-VSV-G, $5 \mu \mathrm{g}$ of pCgpV, and $15 \mu \mathrm{g}$ of pSIH1-H1-siLUC-copGFP plasmids into HEK-293T cells $\left(6 \times 10^{6}\right.$ cells per well) using lipofectamine 2000 (Invitrogen, Carlsbad, CA, USA). The lentiviral supernatants were harvested $72 \mathrm{~h}$ after transfection, filtered through Millex-GP $0.45 \mu \mathrm{m}$ filters (Millipore, Schwalbach, Germany), and concentrated using Retro-Concentin Retroviral Concentration Reagent (System Biosciences, Palo Alto, CA, USA). The titer of lentiviruses was measured with a QuickTiter Lentivirus Titer Kit (Cellbiolabs, San Diego, CA, USA) and stored at $-80^{\circ} \mathrm{C}$.

For the anti-viral test, we co-incubated $2 \mu \mathrm{L}$ of lentivirus soup $\left(2.8 \times 10^{6}\right.$ lentiviruses $\left./ \mu \mathrm{L}\right)$ with $2 \mu \mathrm{L}$ of test sample for $5 \mathrm{~min}$ and $24 \mathrm{~h}$ at $25^{\circ} \mathrm{C}$. After the co-incubation, $2 \mu \mathrm{L}$ from the total $4 \mu \mathrm{L}$ of the test sample-lentivirus mixture was infected in HEK-293T cells $\left(1 \times 10^{4}\right.$ cells per well). Expression of the copGFP protein was observed at day 3 after infection with a Zeiss 510 fluorescence microscope (Carl Zeiss Co., Oberkochen, Germany).

\subsection{Analysis of the Genome}

Genomic analysis of L. plantarum NIBR97 was performed by previously described procedures. In detail, genomic DNA from the NIBR97 was extracted and sequenced by previously described procedures [28]. De novo assembly and putative gene coding sequences (CDSs) from the assembled contigs was performed by the hierarchical genome assembly process (HGAP, Version 3) workflow [30] and the bacterial genome was checked by MUMmer 3.5 [31], identifying that the genome comprises a single circular DNA chromosome of 3,022,780 bp with four plasmids by trimming one of the self-similar ends for manual genome closure (Table 2). Putative gene coding sequences (CDSs) from the assembled contigs were identified by Glimmer v3.02 [32], and the obtained ORFs were examined by Blastall alignment (http://www.ncbi.nlm.nih.gov/books/NBK1762). Gene ontology annotations of the ORFs were assigned by Blast2GO software [33]. In addition, ribosomal RNAs and transfer RNAs were separated by RNAmmer 1.2 and tRNAscan-SE 1.4 [34,35]. Finally, the whole-genome sequence data were deposited as Sequence Read Archive (SRA) data in GenBank (SRA no., SRR12344691; BioProject no., PRJNA647132).

\subsection{Statistical Analysis}

The mean values were separated by the probability difference option according to significant differences. The results are exhibited as least square means with standard deviations. Duncan's multiple range tests (MRT) were applied for verification of significant differences $(p<0.05)$ between sample types. All the analyses were performed by the SAS statistical software package (version 9.1, SAS Inst., Inc., Cary, NC, USA), for which differences were considered significant at $p<0.05$.

\section{Conclusions}

Together, our data showed that the cell-free supernatant from L. plantarum NIBR97, producing novel bacteriocins, has superior antibacterial and antiviral activities during both short and long exposures, which suggests that it is potentially useful as a natural material to completely or partially replace chemical disinfectants. 
Supplementary Materials: The following are available online at http://www.mdpi.com/1424-8247/13/10/0266/s1, Figure S1. Antibacterial activity of cell-free supernatant from L. plantarum NIBR97. Figure S2. Overall features of the L. plantarum NIBR97 genome (contig 1) and plasmids (contig 2 to 5). Figure S3. Antibacterial activity of synthetic plantaricins identified from the L. plantarum NIBR97 genome. Figure S4 Antibacterial activity of the cell-free supernatant from E. coli. Top10 strain, harboring each Pln gene. Figure S5. The content of lactic acid in the cell-free supernatant from L. plantarum NIBR97. Table S1. Identification of ORFs predicted as antimicrobial peptides (AMPs) from the genome assembly data of L. plantarum NIBR97. Table S2. Transcriptomic analysis results of AMPs from L. plantarum NIBR97.

Author Contributions: W.Y.B., I.S.J., and S.W.K. conceived and designed the experiments; S.I.K., D.H.S., S.Y.O., Y.Y., and S.W.K. performed the experiments; C.W.L., Y.K.S., H.-S.Y., and B.-H.L. analyzed the data; S.W.K., B.-H.L., H.-J.A., I.S.J., and W.Y.B contributed reagents/materials/analysis tools; I.S.J. and W.Y.B. wrote the paper. All authors have read and agreed to the published version of the manuscript.

Funding: This research was funded mainly by the National Institute of Biological Resources (NIBR), the Ministry of Environment (MOE) of the Republic of Korea, grant number NIBR202019103. I.S.J. was supported by the National Research Foundation of Korea (NRF) grant funded by the Korean government (Ministry of Science and ICT) (no. 2020R1C1C1007796).

Acknowledgments: The S. Gallinarum, pathogenic E. coli, and S. iniae that are susceptible to AMPs were obtained from Jin Hur (Chonbuk National University, Iksan, Republic of Korea) and Tae Sung Jung (Gyeongsang National University, Jinju, Republic of Korea).

Conflicts of Interest: The authors declare no conflict of interest.

\section{References}

1. World Health Organization. Coronavirus Disease (COVID-19): Situation Report, 150; World Health Organization: Geneva, Switzerland, 2020.

2. World Health Organization. Cleaning and Disinfection of Environmental Surfaces in the Context of COVID-19: Interim Guidance; World Health Organization: Geneva, Switzerland, 2020.

3. Atolani, O.; Baker, M.T.; Adeyemi, O.S.; Olanrewaju, I.R.; Hamid, A.A.; Ameen, O.M.; Oguntoye, S.O.; Usman, L.A. COVID-19: Critical discussion on the applications and implications of chemicals in sanitizers and disinfectants. EXCLI J. 2020, 19, 785. [PubMed]

4. Pradhan, D.; Biswasroy, P.; Ghosh, G.; Rath, G. A review of current interventions for COVID-19 prevention. Arch. Med. Res. 2020, 51, 363-374. [CrossRef]

5. Berardi, A.; Perinelli, D.R.; Merchant, H.A.; Bisharat, L.; Basheti, I.A.; Bonacucina, G.; Cespi, M.; Palmieri, G.F. Hand sanitisers amid CoViD-19: A critical review of alcohol-based products on the market and formulation approaches to respond to increasing demand. Int. J. Pharm. 2020, 584, 119431. [CrossRef] [PubMed]

6. Ibrahim, O.O. Classification of Antimicrobial Peptides Bacteriocins, and the Nature of Some Bacteriocins with Potential Applications in Food Safety and Bio-Pharmaceuticals. EC Microbiol. 2019, 15, 591-608.

7. Stanojević-Nikolić, S.; Dimić, G.; Mojović, L.; Pejin, J.; Djukić-Vuković, A.; Kocić-Tanackov, S. Antimicrobial activity of lactic acid against pathogen and spoilage microorganisms. J. Food Process. Preserv. 2016, 40, 990-998. [CrossRef]

8. Vieco-Saiz, N.; Belguesmia, Y.; Raspoet, R.; Auclair, E.; Gancel, F.; Kempf, I.; Drider, D. Benefits and inputs from lactic acid bacteria and their bacteriocins as alternatives to antibiotic growth promoters during food-animal production. Front. Microbiol. 2019, 10, 57. [CrossRef]

9. Ahmad, V.; Khan, M.S.; Jamal, Q.M.S.; Alzohairy, M.A.; Al Karaawi, M.A.; Siddiqui, M.U. Antimicrobial potential of bacteriocins: In therapy, agriculture and food preservation. Int. J. Antimicrob. Agents 2017, 49, 1-11. [CrossRef]

10. Hashim, H.; Sikandar, S.; Khan, M.A.; Qurashi, A.W. Bacteriocin: The avenues of innovation towards applied microbiology. Pure Appl. Biol. (PAB) 2019, 8, 460-478. [CrossRef]

11. Cerqueira, J.; Dimitrov, S.; Silva, A.; Augusto, L. Inhibition of Herpes simplex virus 1 and Poliovirus (PV-1) by bacteriocins from Lactococcus lactis subsp. lactis and Enterococcus durans strains isolated from goat milk. Int. J. Antimicrob. Agents 2018, 51, 33-37.

12. Ermolenko, E.; Desheva, Y.; Kolobov, A.; Kotyleva, M.; Sychev, I.; Suvorov, A. Anti-Influenza Activity of Enterocin B In vitro and Protective Effect of Bacteriocinogenic Enterococcal Probiotic Strain on Influenza Infection in Mouse Model. Probiotics Antimicrob. Proteins 2019, 11, 705-712. [CrossRef] 
13. Park, S.-C.; Park, Y.; Hahm, K.-S. The role of antimicrobial peptides in preventing multidrug-resistant bacterial infections and biofilm formation. Int. J. Mol. Sci. 2011, 12, 5971-5992. [CrossRef] [PubMed]

14. Jenssen, H.; Hamill, P.; Hancock, R.E. Peptide antimicrobial agents. Clin. Microbiol. Rev. 2006, 19, 491-511. [CrossRef] [PubMed]

15. O'Connor, P.M.; O'Shea, E.F.; Cotter, P.D.; Hill, C.; Ross, R.P. The potency of the broad spectrum bacteriocin, bactofencin A, against staphylococci is highly dependent on primary structure, N-terminal charge and disulphide formation. Sci. Rep. 2018, 8, 1-8.

16. Vescovo, M.; Bottazzi, V.; Torriani, S.; Dellaglio, F. Basic characteristics, ecology and application of Lactobacillus plantarum [in the production of fermented foods of animal and plant origin]: A review. Ann. Microbiol. Enzimol. (Italy) 1993, 43, 261-284.

17. Tremonte, P.; Pannella, G.; Succi, M.; Tipaldi, L.; Sturchio, M.; Coppola, R.; Luongo, D.; Sorrentino, E. Antimicrobial activity of Lactobacillus plantarum strains isolated from different environments: A preliminary study. Int. Food Res. J. 2017, 24, 852-859.

18. Dinev, T.; Beev, G.; Tzanova, M.; Denev, S.; Dermendzhieva, D.; Stoyanova, A. Antimicrobial activity of Lactobacillus plantarum against pathogenic and food spoilage microorganisms: A review. Bulg. J. Vet. Med. 2018, 21, 253-268. [CrossRef]

19. Fjell, C.D.; Hiss, J.A.; Hancock, R.E.; Schneider, G. Designing antimicrobial peptides: Form follows function. Nat. Rev. Drug Discov. 2012, 11,37-51. [CrossRef]

20. Diep, D.B.; Håvarstein, L.S.; Nes, I.F. Characterization of the locus responsible for the bacteriocin production in Lactobacillus plantarum C11. J. Bacteriol. 1996, 178, 4472-4483. [CrossRef]

21. Young, R. Bacteriophage holins: Deadly diversity. J. Mol. Microbiol. Biotechnol. 2002, 4, 21-36.

22. Nissilä, E.; Douillard, F.P.; Ritari, J.; Paulin, L.; Järvinen, H.M.; Rasinkangas, P.; Haapasalo, K.; Meri, S.; Jarva, H.; De Vos, W.M. Genotypic and phenotypic diversity of Lactobacillus rhamnosus clinical isolates, their comparison with strain GG and their recognition by complement system. PLoS ONE 2017, 12, e0176739.

23. Karpiński, T.M. Efficacy of octenidine against Pseudomonas aeruginosa strains. Eur. J. Biolog. Res. 2019, 9, 135-140.

24. Hsieh, I.-N.; Hartshorn, K.L. The role of antimicrobial peptides in influenza virus infection and their potential as antiviral and immunomodulatory therapy. Pharmaceuticals 2016, 9, 53. [CrossRef] [PubMed]

25. Ahmed, A.; Siman-Tov, G.; Hall, G.; Bhalla, N.; Narayanan, A. Human antimicrobial peptides as therapeutics for viral infections. Viruses 2019, 11, 704. [CrossRef] [PubMed]

26. Desriac, N.; Broussolle, V.; Postollec, F.; Mathot, A.-G.; Sohier, D.; Coroller, L.; Leguerinel, I. Bacillus cereus cell response upon exposure to acid environment: Toward the identification of potential biomarkers. Front. Microbiol. 2013, 4, 284. [CrossRef] [PubMed]

27. Wiegand, I.; Hilpert, K.; Hancock, R.E. Agar and broth dilution methods to determine the minimal inhibitory concentration (MIC) of antimicrobial substances. Nat. Protoc. 2008, 3, 163. [CrossRef] [PubMed]

28. Kim, S.W.; Ha, Y.J.; Bang, K.H.; Lee, S.; Yeo, J.-H.; Yang, H.-S.; Kim, T.-W.; Lee, K.P.; Bang, W.Y. Potential of Bacteriocins from Lactobacillus taiwanensis for Producing Bacterial Ghosts as a Next Generation Vaccine. Toxins 2020, 12, 432. [CrossRef]

29. Jang, Y.; Shin, J.S.; Lee, J.-Y.; Shin, H.; Kim, S.J.; Kim, M. In Vitro and In Vivo Antiviral Activity of Nylidrin by Targeting the Hemagglutinin 2-Mediated Membrane Fusion of Influenza A Virus. Viruses 2020, 12, 581. [CrossRef] [PubMed]

30. Chin, C.-S.; Alexander, D.H.; Marks, P.; Klammer, A.A.; Drake, J.; Heiner, C.; Clum, A.; Copeland, A.; Huddleston, J.; Eichler, E.E. Nonhybrid, finished microbial genome assemblies from long-read SMRT sequencing data. Nat. Methods 2013, 10, 563-569. [CrossRef] [PubMed]

31. Kurtz, S.; Phillippy, A.; Delcher, A.L.; Smoot, M.; Shumway, M.; Antonescu, C.; Salzberg, S.L. Versatile and open software for comparing large genomes. Genome Biolog. 2004, 5, R12. [CrossRef]

32. Delcher, A.L.; Bratke, K.A.; Powers, E.C.; Salzberg, S.L. Identifying bacterial genes and endosymbiont DNA with Glimmer. Bioinformatics 2007, 23, 673-679. [CrossRef]

33. Conesa, A.; Götz, S.; García-Gómez, J.M.; Terol, J.; Talón, M.; Robles, M. Blast2GO: A universal tool for annotation, visualization and analysis in functional genomics research. Bioinformatics 2005, 21, 3674-3676. [CrossRef] [PubMed] 
34. Lagesen, K.; Hallin, P.; Rødland, E.; Stærfeldt, H.; Rognes, T.; Ussery, D. RNammer: Consistent annotation of rRNA genes in genomic sequences. Nucleic Acids Res. 2007, 35, 3100-3108. [CrossRef] [PubMed]

35. Lowe, T.M.; Eddy, S.R. tRNAscan-SE: A program for improved detection of transfer RNA genes in genomic sequence. Nucleic Acids Res. 1997, 25, 955-964. [CrossRef] [PubMed]

(C) 2020 by the authors. Licensee MDPI, Basel, Switzerland. This article is an open access article distributed under the terms and conditions of the Creative Commons Attribution (CC BY) license (http://creativecommons.org/licenses/by/4.0/). 